\title{
Normas editoriales y éticas para la publicación de artículos.
}

Los trabajos que se presenten para su publicación en la Revista de Derecho Público deberán ceñirse a las normas que a continuación se indican, reservándose el Comité Editorial de la Revista el derecho de declarar inadmisible aquellos que se aparten de lo indicado o devolverlo al autor para que introduzca las correcciones correspondientes.

\section{Temas de interés y periodicidad.}

1. La Revista de Derecho Público publica trabajos de investigación originales e inéditos relacionados con la especialidad dogmática del Derecho Constitucional y Administrativo.

2. Los interesados pueden enviar: estudios (monografías o artículos doctrinarios), comentarios de jurisprudencia, noticias y recensiones o reseñas bibliográficas.

\section{Entrega de originales.}

1. Los trabajos se entregarán en idioma castellano, en papel y, además, en soporte electrónico, escritos en Microsoft Word o en formato compatible (disquete, CD-ROM o por correo electrónico), a la dirección de la Revista de Derecho Público.

2. Los estudios y comentarios de jurisprudencia deberán ser escritos con letra Arial, tamaño 12, con interlineado simple. Su extensión total no deberá superar las 25 páginas tamaño carta, incluidas notas a pie de página, bibliografía y apéndices en su caso. Al inicio se incluirá el título, nombre del autor o autores y se indicará en una nota a pie de página su profesión, grados académicos, lugar de desempeño académico o profesional y su correo electrónico. Esta nota, así como cualquier otra referencia o agradecimientos, no se regirá por el sistema numérico sino que se indicará utilizando un asterisco como símbolo, antes de las notas con numeración correlativa.

3. Cada trabajo será precedido de un resumen escrito en castellano y en inglés de 200 caracteres máximo y con tres a cinco palabras clave en ambos idiomas. El título también deberá estar escrito en ambos idiomas.

4. Los trabajos no deberán contener textos subrayados ni utilizar el formato de letras "negritas". Si el autor desea realzar una expresión deberá utilizar letras cursivas e igualmente si introduce un término en idioma extranjero. Las "negritas" solo deben utilizarse para la identificación de las distintas secciones del trabajo, para lo cual deberán usarse números romanos; enseguida números arábigos seguidos de un punto; y luego letras minúsculas con paréntesis; y, finalmente, en caso de utilizarse una nueva subdivisión, esta se identificará mediante números romanos en minúscula con paréntesis. 


\section{Compromiso con el editor, copyright y arbitraje}

1. El envío de un original supone el compromiso por parte del autor de no someterlo simultáneamente a la consideración de otras publicaciones periódicas, y que el autor o los autores de las colaboraciones ceden a la Revista de Derecho Público los derechos de reproducción de los textos admitidos.

2. Los editores decidirán la publicación de los trabajos, requiriendo siempre al menos dos informes de evaluadores pares anónimos, los que serán externos a la institución cuando los trabajos pertenezcan a la Facultad de Derecho de la Universidad de Chile. Los originales no serán devueltos.

\section{Normas sobre referencias bibliográficas.}

1. Para las referencias bibliográficas deberán aplicarse las siguientes normas técnicas:

1.1 NCh1143.Of.1999, norma técnica nacional equivalente a la norma ISO 690:1987, Documentación - Referencia Bibliográficas - Contenido, forma y estructura.

1.2 NCh1143/2.Of2003, equivalente a la norma ISO 690-2, Información y documentación -referencias bibliográficas-. Parte 2: Documentos electrónicos o parte de ellos.

2. Cada trabajo debe incluir sus fuentes de información identificando el autor y fecha de publicación de los libros, revistas, tesis y otros documentos utilizados. Este método de citar en el texto mismo apellido del autor, fecha de publicación y página, permiten al lector localizar la fuente de información en orden alfabético, en la lista de referencias al final del trabajo.

Ej.: Ferrajoli (2006), p.22.

\section{Referencias de bibliografía, normas y jurisprudencia}

1. Al final del trabajo se incluirá una sección titulada en Bibliografía, con las referencias completas de bibliografía, normas y jurisprudencia citadas, bajo el título de "Referencias bibliográficas".

2. "Bibliografía citada". Todas las referencias a libros, artículos de revista, capítulos y formatos electrónicos efectivamente citados se ordenarán alfabéticamente por el primer apellido de su autor, luego el nombre de pila, título de la obra, tomo, editorial, ciudad, año y número total de páginas. En toda citación el o los apellidos del autor se escribirán en Versales, el nombre en redonda y la obra en cursiva. Ejemplos de cita:

2.1 Libro: SILVA BASCUÑÁN, Alejandro (2010): Tratado de Derecho Constitucional Tomo XIII, Editorial Jurídica de Chile, Santiago, 438 pp.

2.2. Traducciones: DAMASKA, MYRJAN (2000): Las caras de la justicia y el poder del Estado (traducc., Ruiz-Tagle Vial, Pablo), Editorial Jurídica de Chile, Santiago, 430 pp.

2.3. Capítulos de libros: AYLWIN AZÓCAR, Patricio (2009): "Evolución y progreso del régimen jurídico de la Administración del Estado de Chile”, en: Pantoja Bauzá, Rolando (coord.), Derecho Administrativo. 150 ańos de doctrina, Editorial Jurídica de Chile, Santiago pp.157-166. 
2.4. Artículo de revista: FERRAJOLI, Luigi (2008): "Las libertades en los tiempos del liberalismo”, en: Revista de Derecho Público Vol. 70, pp. 11-21.

2.5. Documentos en formato electrónico: Ejemplo: Rodríguez Fernández, Ignacio (2005). La Responsabilidad Patrimonial por Acto Administrativo. Comentario a una reciente monografía espańola. [en línea]: Revista de Derecho Consejo de Defensa del Estado en Internet [fecha de consulta: 20 Noviembre 2006]. Disponible en: http://www.cde.cl/revista.php?id=201.

3. Normas citadas. Se deberá considerar al final del trabajo, en un listado, todas las referencias legales o normativas efectivamente referidas, bajo el título: NORMAS CITADAS. Se indicarán, en el caso de una ley: Número de la ley y denominación oficial si la tiene/Título de la publicación en que aparece oficialmente/Fecha (día, mes y año).

Ej.; Ley No 19.880, Establece bases de los procedimientos administrativos que rigen los actos de los órganos de la Administración del Estado. Diario Oficial, 29 mayo 2003.

Sólo se admiten abreviaturas de normas si el autor ofrece un listado alfabético. Ejemplo para la Ley señalada: LBPA.

4. Jurisprudencia citada. Se deberá considerar al final del trabajo, en un listado, titulado JURISPRUDENCIA CITADA todas las referencias jurisprudenciales. Las sentencias se ordenarán cronológica y alfabéticamente por el nombre de las partes, con indicación del tribunal, la fecha y la sede de edición.

Ejemplo: Tamaya con Atocha (1999): Corte Suprema 6 abril 1999, en: Revista de Derecho y Jurisprudencia, tomo 96 (1999) II, sección 7a , pp. 65-73.

5. Los dictámenes de la Contraloría General de la República se citarán de acuerdo a su número y año.

\section{Referencias abreviadas en las notas (al pie de página)}

1. Todas las notas irán al pie de la página, numeradas mediante caracteres arábigos y en formato superíndice, en que se incluirán las referencias o citas abreviadas a obras, normas y jurisprudencia, y solo excepcionalmente se admitirán textos de desarrollo. Opcionalmente, todas las referencias abreviadas pueden incluirse entre paréntesis en el texto principal en cuyo caso no habrá notas al pie de página.

2. Referencia abreviada de Obras. En las referencias abreviadas a libros, artículos de revista y demás formatos se señalará en la nota al pie: solo el primer apellido del autor, en versales, el año (entre paréntesis) y el número o números de la página o de las páginas precisas en que aparece la referencia citada.

2.1. Obras con un autor: Cassagne (2006) p. 52. / Moderne (2005) p.113.

2.2. Obras con dos autores (los apellidos se unen por medio de la conjunción y): García de Enterría y Fernández (2006) tomo I, p. 392

2.3. Si una obra tiene más de dos autores, se citan todos los autores en la lista de referencias final, pero en las referencias a pie de página se escribe solamente el apellido del primer autor seguido de et al. [del latín et alii: y otros], año de publicación y página respectiva: Verdugo et al. (2002) p. 94. 
2.4. Citas textuales: Las citas textuales deben ir entre comillas, e incluir el apellido del autor, año de publicación y la página de donde se obtuvo la cita (Nohlen 2004, p. 67).

2.5. Si se citan dos o más obras de un determinado autor, publicadas en el mismo año, se distinguirán por medio de una letra. Ejemplo: Nohlen (2005a) y Nohlen (2005b).

2.6. En caso que la obra vuelva a ser citada posteriormente, se utilizará la expresión "Ibid" en cursivas, indicando la página en caso que la nueva cita corresponda a una página distinta a la de la cita anterior.

3. Referencia abreviada de Normas. Se deberá indicar, en su caso, el número de la ley y su año. Los lectores podrán verificar los datos completos de la ley citada en el listado de "Normas citadas", al final del trabajo (que se describe más arriba).

Ejemplo: Ley No 19.880, de 2003.

4. Referencias abreviadas de Jurisprudencia. Las citas a pie de página de jurisprudencia deben indicar solo el nombre de las partes, en cursiva y la fecha (entre paréntesis); en caso que se trate de sentencias del Tribunal Constitucional se citara el rol y fecha de la sentencia. De este modo, los lectores podrán verificar los datos completos de la sentencia citada en el listado de "Jurisprudencia citada", al final del trabajo (que se describe más arriba).

Ejemplo: Granja con Fisco (1938).

\section{Políticas de evaluación.}

1. La Revista de Derecho Público contempla un sistema de evaluación por pares, es decir, cada artículo se somete a la evaluación de expertos en la disciplina.

2. En cuanto al procedimiento de evaluación, previa indicación de la fecha de recepción, los artículos se seleccionan en atención al contenido considerando su aporte a la especialidad, tanto desde el punto de vista académico como del ejercicio profesional del abogado; asimismo, se evalúa la importancia, originalidad y actualidad del tema desarrollado, y la proyección que el artículo pueda tener como fuente de futuras investigaciones. Especial revisión se otorga a la presentación y redacción de los artículos y a las fuentes bibliográficas empleadas.

3. Aprobado el trabajo por alguno de los miembros del Consejo Editorial, se inicia el procedimiento de revisión por pares Double-blind, siendo examinado por al menos dos especialistas externos al Consejo Editorial, tanto nacionales como extranjeros, el que culmina con el dictamen emitido por los evaluadores, el cual puede ser de aceptación, o de aceptación con modificaciones, o de rechazo (si se presentan dictámenes incompatibles se contempla un tercer árbitro que zanje la decisión). En caso de la aceptación del artículo, se le informa al autor su próxima publicación; si el artículo es aceptado con modificación, se le remite al autor las observaciones respectivas para su corrección y si el artículo resulta rechazado se le informa el autor, haciéndosele llegar el dictamen ciego con las razones de la decisión de los evaluadores. 


\section{Declaración de normas éticas y malas prácticas.}

1. La Revista de Derecho Público está comprometida con la comunidad académica en garantizar la ética y calidad de los artículos publicados, en concordancia con los valores y principios que inspiran la labor de difusión y cultivo del conocimiento que le corresponde a la Universidad de Chile.

2. Para el logro de dicho objetivo, el comité editorial de la revista implementará los resguardos, mecanismos y procedimientos adecuados que permitan asegurar el contenido de los artículos, su calidad, su autenticidad y originalidad.

3. En ese sentido, la revista dispone de un sistema de arbitraje que sigue para la selección de artículos, así como los criterios de evaluación que deben aplicar los evaluadores externos -anónimos y por pares, ajenos al Consejo Editorial-. Asimismo, a final de cada año, se publica el listado de los árbitros que han colaborado con el número, el número de artículos rechazados, aceptados y aceptados con modificaciones.

4. Por otra parte, la revista contempla mecanismos destinados a evitar los conflictos de intereses en la publicación de artículos de investigación, esto es, aquellos manuscritos que se puedan encontrar influidos por un interés secundario, de tipo generalmente económico, institucional o personal. El conflicto de interés se puede originar en distintos procesos de revisión del artículo: la redacción, la revisión y su publicación, recociendo a los sujetos afectados por dicho conflicto al autor (o autores), par revisor (o árbitro) y al editor (o equipo editorial).

4.1. Al remitir un manuscrito a la revista, los autores deberán reconocer y declarar sus relaciones económicas, institucionales o cualquier otro conflicto de intereses que pudieran sesgar su trabajo. Los autores deben declarar en el manuscrito todo apoyo financiero recibido (estatal o privado) o personales para la realización del trabajo.

Para ello se ha dispuesto el Formulario de Conflicto de Intereses para Autores.

4.2. Los pares que actúan como revisores externos deben informa el editor o dirección de la revista cualquier conflicto de intereses que pudiera sesgar sus juicio o dictamen sobre el artículo sometido a su revisión y deben excusarse de revisarlo si lo consideran oportuno.

Para ello se ha dispuesto el Formulario de Conflicto de Intereses para Árbitros.

Los árbitros o revisores no deben hacer uso de su lectura del trabajo para favorecer sus propios intereses, antes de que el manuscrito sea publicado.

4.3. El equipo editorial de la revista encargado de guiar el proceso de edición y publicación de los artículos no deben tener compromisos económicos, institucionales o personales en ninguna de las materias que juzgarán.

Todo miembro del equipo editorial que participe en el proceso editorial deberá proporcionar al cuerpo editorial una descripción actualizada de sus propios intereses (que pudieran afectar sus juicios editoriales) y marginarse de cualquier decisión en la cual pudieran tener conflicto de intereses.

En la publicación final de los artículos científicos, así como de cualquier artículo o documento que se publique en las secciones de la revista deberán incluir una descripción del apoyo económico prestado 
para su elaboración (sea de fuente privada o pública - estatal) y cualquier conflicto de intereses que, a juicio del equipo editorial, deban conocer los lectores.

Queda estrictamente prohibido la utilización de la información adquirida durante el proceso editorial para el aprovechamiento personal por parte de los miembros del equipo editorial.

5. La revista garantiza en todo momento la confidencialidad del proceso de evaluación: el anonimato de los evaluadores y de los autores; el contenido evaluado; el informe razonado emitidos por los evaluadores y cualquier otra comunicación emitida por los consejos editorial, asesor y científico si así procediese.

6. Finalmente, esta publicación enfatiza en la prohibición estricta de textos plagiados o utilizados de forma fraudulenta, los cuales, de ser detectados, serán eliminados o no publicados de la revista, con la correspondiente nota explicativa a los lectores.

7. Al aceptar los términos y acuerdos expresados por nuestra revista, los autores han de garantizar que el artículo y los materiales asociados a él son originales o no infringen derechos de autor. 